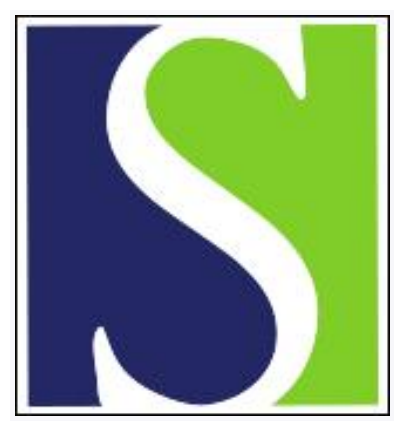

Scand J Work Environ Health 1979;5(3):249-256

https://doi.org/10.5271/sjweh.3098

Issue date: Sep 1979

Diagnosis of Raynaud's phenomenon in quarrymen's traumatic vasospastic disease

by Olsen $\mathrm{N}$, Nielsen $\mathrm{SI}$

Affiliation: Department of Clinical Physiology, Hvidovre Hospital, DK-2650 Hvidovre, Denmark.

Key terms: body cooling; diagnostics; finger cooling; finger systolic blood pressure; quarryman; quarrymen; Raynaud's phenomenon; traumatic vasospastic disease

This article in PubMed: www.ncbi.nlm.nih.gov/pubmed/20120572

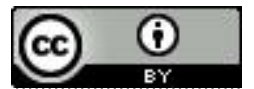




\title{
Diagnosis of Raynaud's phenomenon in quarrymen's traumatic vasospastic disease
}

\author{
by NIELS OLSEN, M.D., ${ }^{1}$ and STEEN L. NIELSEN, M.D. ${ }^{2}$
}

\begin{abstract}
OLSEN, N. and NIELSEN, S. L. Diagnosis of Raynaud's phenomenon in quarrymen's traumatic vasospastic disease. Scand. $j$. work environ. \& health 5 (1979) 249256. An epidemiologic and clinical study of traumatic vasospastic disease (TVD) was carried out involving 18 workers in a granite quarry. The prevalence of TVD was found to be $72 \%$ (95\% confidence limits $47-90 \%)$ estimated from the combined information from a questionnaire and a clinical interview. The fingers of the hand contralateral to the preferred working hand were the most frequently affected. A newly developed cold provocation test measuring reduction in finger systolic blood pressure during combined body and finger cooling was applied to the quarrymen and to 20 age-matched men in a reference group. Raynaud's phenomenon with digital arterial closure was verified by the measurement of zero pressure in the test finger at 15 or $6^{\circ} \mathrm{C}$ in 12 of 13 quarrymen with anamnestic and clinical evidence of TVD. The test showed an abnormal response as compared to that of the reference group in all the workers having used vibrating hand tools for more than five years. The precision, estimated as $95 \%$ confidence limits from double determinations, was $18.7 \%$. The cold provocation test can be employed diagnostically, and it can also be used to observe the effects of prophylactic measures.
\end{abstract}

Key words: body cooling, finger cooling, finger systolic blood pressure, quarrymen, Raynaud's phenomenon, traumatic vasospastic disease.

Traumatic vasospastic disease (TVD) is a secondary Raynaud's phenomenon caused by vibrating hand tools. Other descriptive synonyms are "Raynaud's phenomenon of occupational origin" and "vibration-induced white finger" (12). The diagnosis of TVD demands an observation of Raynaud's phenomenon, an elimination of primary and other secondary etiologies, and a his-

1 Department of Clinical Physiology, Hvidovre Hospital, University of Copenhagen, Denmark.

2 Department of Clinical Physiology, Herlev Hospital, University of Copenhagen, Denmark.

Reprint requests to: Mr. Niels Olsen, Department of Clinical Physiology, Hvidovre Hospital, DK-2650 Hvidovre, Denmark. tory of vibration exposure. Raynaud's phenomenon is characterized by episodes of well-demarcated pallor on exposure to cold, usually affecting one or more fingers and often accompanied by numbness, cyanosis and paresthesia (11). The termination of an attack may be followed by redness of the digit, pain and throbbing. The pallor has been ascribed to closure of the digital arteries (5). Investigations of the frequency and severity of TVD are usually performed with the use of questionnaires (13). Until now objective methods have failed to detect all subjects with complaints $(8,12)$. The lack of adequate diagnostic methods has made it difficult to obtain an understanding of the pathogenic mechanism (15) and to control prophylactic measures in occupational medicine. 
Table 1. Number, age distribution, and smoking habits of the groups studied.

\begin{tabular}{|c|c|c|c|c|c|c|}
\hline \multirow{2}{*}{ Group } & \multirow{2}{*}{$\mathbf{N}$} & \multicolumn{2}{|c|}{ Age (years) } & \multirow{2}{*}{$\begin{array}{l}\text { Number of } \\
\text { smokers }\end{array}$} & \multicolumn{2}{|c|}{ Grams of tobacco/d } \\
\hline & & Median & Range & & Median & Range \\
\hline Vibration-exposed & 18 & 50 & $21-65$ & 12 & 17 & $2-40$ \\
\hline Reference & 20 & 37 & $26-57$ & 10 & 13 & $10-20$ \\
\hline
\end{tabular}

Recently we described a method for routinely investigating Raynaud's phenomenon using finger systolic blood pressure measurements after the cooling of one finger to disclose the digital artery vasospasm (7). In the present study the method was applied to a group of vibration-exposed stonecutters and a reference group. The results were compared to information from a questionnaire controlled by a medical interview. The study is a part of an investigation on the prevalence of TVD in Denmark.

\section{MATERIAL AND METHODS}

\section{Populations studied}

The investigation included all the employees of a Danish granite quarry. Of the 20 men working in the firm, 18 volunteered to participate in the investigation and two were absent. All 18 employees in the vibration-exposed group worked outdoors regularly at the granite quarry using vibrating hand tools. The work involved the use of pneumatic hammers for nine, pneumatic chisels for five, and the combined use of the two for two subjects. Two used pneumatic drills. Thirteen workers used gloves, but there were no other attempts to reduce tool vibration. None of the 18 employees had primary Raynaud's phenomenon or constitutional "dead fingers." Included was a 49-yearold man with medically treated arterial hypertension and an arm blood pressure of $155 / 100 \mathrm{~mm} \mathrm{Hg}$. Five subjects had been treated at hospitals for injuries of the hands or fingers, but the medical interview indicated that these injuries were not causing Raynaud's phenomenon. The cold provocation test was applied to noninjured fingers.

As all employees had been using vibrating hand tools, it was not possible to investigate a reference group from this firm. Therefore a reference group comprising 20 age-matched males who worked outdoors in a shipyard were investigated. The referents were selected consecutively according to the following criteria, validated in a medical interview: outdoor-working male, never worked with vibrating hand tools, without primary Raynaud's phenomenon and constitutional "dead fingers," no secondary causes of Raynaud's phenomenon. None of the 20 referents suffered from vascular or metabolic disorders. One had been treated for an injury of the left hand, and therefore the right hand was examined in the cold provocation test.

The analyses were carried out on the 20 referents and 18 vibration-exposed subjects. The age distribution, number of smokers, and daily tobacco consumption did not differ significantly between the two groups (table 1). Both groups were investigated in the middle of the month of November, but with an interval of one year. The outdoor climate and temperature was nearly the same in the two situations (temperatures about $15^{\circ} \mathrm{C}$ ).

\section{Methods}

All 38 males answered a questionnaire concerning their work conditions (type of vibrating hand tool and duration of use), finger symptoms (9), smoking habits, treatment for hand injury, and treatment for other diseases (diabetes mellitus, arterial hypertension, ischemic heart or 
leg disease). The answers to the questionnaire were controlled and supplemented in a medical interview. Raynaud's phenomenon was defined as cold provoked episodes of well-demarcated pallor affecting one or more fingers (11), and "dead fingers" was defined as a feeling of numbness in one or more fingers even in moderately cold weather. The stage assessments of TVD were based on the combined information from the questionnaire and the interview in accordance with the principles described by Taylor and Pelmear (12).

The following stages were used:

Stage 0: no symptoms.

Stage $0_{N} / 0_{T}$ : intermittent numbness or tingling but no interference with work or domestic and social activities.

Stage 1: blanching of one or more finger tips without any interference with work or domestic and social activities.

Stage 2: blanching characterized by increased frequency and number of fingers affected, usually triggered by cold. There is slight interference with domestic and social activities but not with work.

Stage 3: extensive blanching with frequent episodes in summer, as well as winter. There is definite interference with work and domestic and social activities.

Stage 4: extensive blanching affecting all digits both in summer and in winter, leading to a change of occupation.
The men in the intermediate stage of $0_{\mathrm{N}} / 0_{\mathrm{T}}$ were not considered to have reached the white finger stage. The prevalence of TVD was defined as the percentage of stages 1,2 and 3 in the vibration-exposed group.

At the clinical investigation the subjects were investigated in the supine position after $10 \mathrm{~min}$ of rest with their fingers at heart level. They were dressed in indoor clothing. Body cooling was performed by the cooling of the frontal part of the body with a cooling blanket perfused with water at $8-12^{\circ} \mathrm{C}$ from $10 \mathrm{~min}$ before the finger pressure recording until the last measurement. The clinical investigation comprised measurement of arm blood pressure, measurement of finger systolic blood pressure (FSP) on the finger most frequently showing Raynaud's phenomenon, and measurement of FSP on a nonaffected reference finger, usually the thumb. Arm blood pressure was measured auscultatorily with a $12 \times 28 \mathrm{~cm}$ broad cuff on the upper arm. FSP was measured with a cuff on the midphalanx and a mercury-in-rubber strain gauge on the outer phalanx (3) (fig. 1). FSP was defined as the highest cuff pressure during continuous deflation at which an increase in digital volume could be detected by visual inspection of the scan curves of a plethysmograph (Medimatic A/S, Denmark) (fig. 2). Cooling was performed with a double inlet cuff on the midphalanx during 5-min ischemia produced with an occluding cuff on the proximal phalanx (7). FSP was measured by the cooling cuff after cooling to 30,15 and

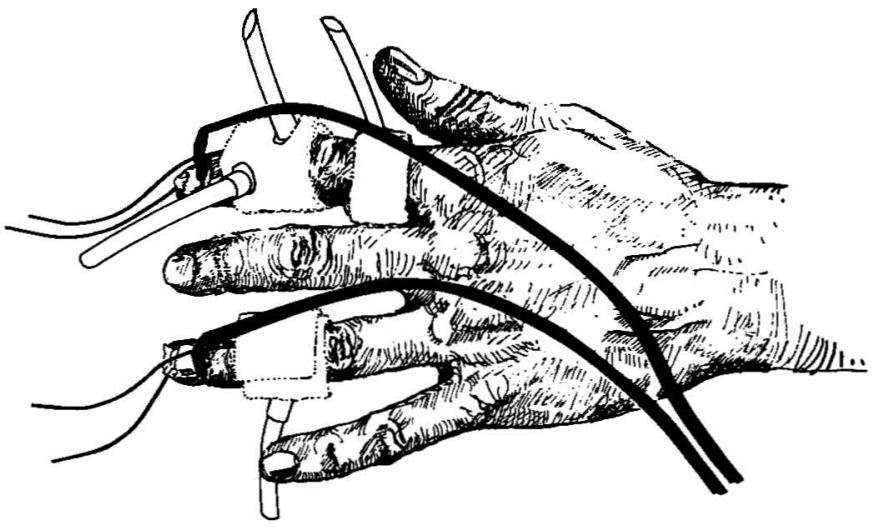

Fig. 1. Blood pressure cuffs on the midphalanx of the second and fourth fingers with a mercury-in-rubber strain gauge on the outer phalanx and thermocouples beneath the pressure cuffs. The double-inlet cuff on the second finger can be pressurized or perfused with water at preset temperatures. The cuff on the proximal phalanx of this finger is used as a tourniquet during the cooling of the midphalanx. 


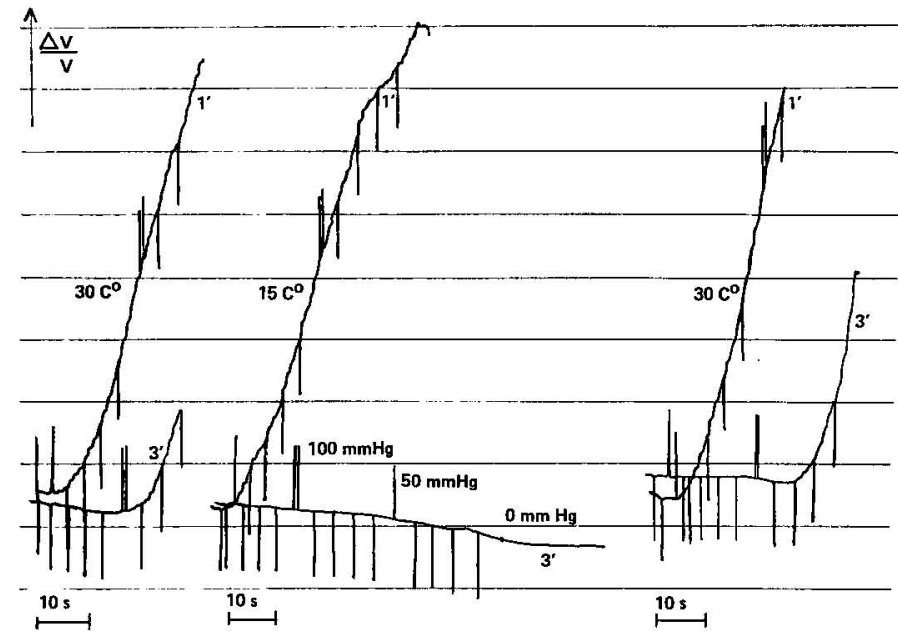

Fig. 2. Records of pulse volume DC signals of the third right finger $\left(3^{\prime}\right)$ at a temperature regulated at 30 and $15^{\circ} \mathrm{C}$ and the right thumb (1') during continuous deflation of cuff pressures. The cuff pressure is indicated by vertical bars with a distance of $10 \mathrm{~mm} \mathrm{Hg}$; two and one upright bars denote 100 and $50 \mathrm{~mm} \mathrm{Hg}$, respectively. Finger systolic pressure, defined as highest cuff pressure at which volume pulse can be recorded, is zero at $15^{\circ} \mathrm{C}$ in the third finger, but it is nearly regained when rewarmed to $30^{\circ} \mathrm{C}$. $6^{\circ} \mathrm{C}$. Water at these temperatures was obtained by the mixing of water from thermobaths at $35^{\circ} \mathrm{C}$ and $2^{\circ} \mathrm{C}$ in a widebore return-valve. The temperatures were recorded on a potentiometer recorder by thermocouples placed on the skin beneath the cuffs. Finger systolic pressure at each of the two lower temperatures $(x)$ in the cooled finger $\left(\mathrm{FSP}_{\mathrm{th}, \mathrm{x}}\right)$ was expressed as the percentage of the pressure at $30^{\circ} \mathrm{C}$ in the same finger ( $\left.\mathrm{FSP}_{\text {th }, 30}\right)$ corrected for changes in arterial pressure of the hand during the investigation:

$\mathrm{FSP}_{\mathrm{x}} \%=\frac{100 \cdot \mathrm{FSP}_{\text {th, } \mathrm{x}}}{\mathrm{FSP}_{\text {th }, 30}-\left(\mathrm{FSP}_{\mathrm{ref}, 30}-\mathrm{FSP}_{\mathrm{ref}, \mathrm{x}}\right)^{\prime}}$

where $\mathrm{FSP}_{\mathrm{ref}, 30}$ and $\mathrm{FSP}_{\text {ref, } x}$ is the pressure in the noncooled reference finger of the same hand, measured at the same time as $\mathrm{FSP}_{\text {th, } 30}$ and $\mathrm{FSP}_{\text {th }, \mathrm{x}}$. By the cold provocation test, Raynaud's phenomenon with digital arterial closure (5) was verified by FSP $\%$ being zero in the test finger at 15 or $6{ }^{\circ} \mathrm{C}$.

All 38 subjects underwent the cold provocation test. There was no difference between the reference group and the vibration-exposed group with respect to room temperature (range $15-19^{\circ} \mathrm{C}$ ), temperature of water to the cooling blanket (range $8-12^{\circ} \mathrm{C}$ ), temperature of reference finger (range $20-35^{\circ} \mathrm{C}$ ), and temperature of test finger at $30^{\circ} \mathrm{C}$ (range $27-33^{\circ} \mathrm{C}$ ), $15^{\circ} \mathrm{C}$ (range $13-16^{\circ} \mathrm{C}$ ) or at $6^{\circ} \mathrm{C}$ (range $\left.5-8^{\circ} \mathrm{C}\right)$. The difference in temperature between the reference and test fingers at $30^{\circ} \mathrm{C}$ was not significant within the groups. The precision of the cold provocation test was estimated for randomly selected vibration-exposed subjects with the use of double determinations with an interval of 5-10 min.

\section{Statistical methods}

Statistical evaluation was performed with nonparametric statistics with a significance limit of 0.05 (two-sided). The difference in numerical measurements between two independent samples was tested with the Mann-Whitney rank sum test. The difference in numerical measurements between two related samples was tested with the Wilcoxon matched-pairs signed rank test; if the number of zeroes in the estimated differences was more than $10 \%$, the Pratt signed rank test was used. The difference in classification between two independent samples was tested with the Fisher exact test when the total number was 60 or smaller, and with the chi-square test when the total number was higher than 60 . In the estimations of variations from double determinations, the $95 \%$ confidence limits of single determinations was calculated as $t \sqrt{\sum \mathrm{d}^{2} / 2 \mathrm{n}}$, where $t$ is "Students $t$," $d$ is the difference between two measurements in a double determination, and $n$ is the number of double determinations. Lower normal limits of FSP $\%$ at 15 and $6^{\circ} \mathrm{C}$ were calculated as $\mathrm{FSP} \%$ (mean) - $\mathbf{t} \cdot \mathbf{S D}$, where $t$ is 